\title{
Neuroendocrine Control of Macrophage Development and Function
}

\begin{abstract}
Arnon Dias Jurberg ${ }^{1,2}$, Vinícius Cotta-de-Almeida ${ }^{1,2}$, Jairo Ramos Temerozo ${ }^{1,2}$, Wilson Savino ${ }^{1,2}$, Dumith Chequer Bou-Habib ${ }^{1,2 *}$ and Ingo Riederer ${ }^{1,2 *}$

'Laboratory on Thymus Research, Oswaldo Cruz Institute/Oswaldo Cruz Foundation, Rio de Janeiro, Brazil, ${ }^{2}$ Brazilian National Institute of Science and Technology on Neuroimmunomodulation (INCT-NIM), Rio de Janeiro, Brazil
\end{abstract}

\section{OPEN ACCESS}

Edited by:

Julie Lasselin,

Stockholm University, Sweden

Reviewed by:

Harald Engler,

Universitätsklinikum Essen,

Germany

Manfred Schedlowski, Universität Duisburg-Essen,

Germany

Robert Adam Harris, Karolinska Institutet (KI),

Sweden

*Correspondence:

Dumith Chequer Bou-Habib

dumith@ioc.fiocruz.br,

dumith.chequer@gmail.com;

Ingo Riederer

riederer@ioc.fiocruz.br,

ingoriederer@hotmail.com

Specialty section:

This article was submitted to Multiple Sclerosis and Neuroimmunology,

a section of the journal

Frontiers in Immunology

Received: 28 February 2018

Accepted: 11 June 2018

Published: 25 June 2018

Citation:

Jurberg $A D$, Cotta-de-Almeida $V$ Temerozo JR, Savino W, BouHabib DC and Riederer I (2018)

Neuroendocrine Control of

Macrophage Development and

Function.

Front. Immunol. 9:1440. doi: 10.3389/fimmu.2018.01440
Macrophages carry out numerous physiological activities that are essential for both systemic and local homeostasis, as well as innate and adaptive immune responses. Their biology is intricately regulated by hormones, neuropeptides, and neurotransmitters, establishing distinct neuroendocrine axes. The control is pleiotropic, including maturation of bone marrow-derived myeloid precursors, cell differentiation into functional subpopulations, cytotoxic activity, phagocytosis, production of inflammatory mediators, antigen presentation, and activation of effector lymphocytes. Additionally, neuroendocrine components modulate macrophage ability to influence tumor growth and to prevent the spreading of infective agents. Interestingly, macrophage-derived factors enhance glucocorticoid production through the stimulation of the hypothalamic-pituitary-adrenal axis. These bidirectional effects highlight a tightly controlled balance between neuroendocrine stimuli and macrophage function in the development of innate and adaptive immune responses. Herein, we discuss how components of neuroendocrine axes impact on macrophage development and function and may ultimately influence inflammation, tissue repair, infection, or cancer progression. The knowledge of the crosstalk between macrophages and endocrine or brain-derived components may contribute to improve and create new approaches with clinical relevance in homeostatic or pathological conditions.

Keywords: macrophages, monocytes, neuroendocrine system, hormones, neurotransmitters, stress, glucocorticoids

\section{INTRODUCTION}

Integration of body functions relies on distinct mechanisms encompassing various organs and systems. As a consequence, perturbations in the environment or in tissue homeostasis usually produce quick and effective responses that may result in significant local and systemic impacts, for example, due to a sustained communication between the central nervous system (CNS) and peripheral organs through the concerted activities of cell type-specific chemical messengers. Major neuroendocrine axes comprise the hypothalamus and the pituitary in the brain signaling to adrenal glands [hypothalamus-pituitary-adrenal (HPA) glands or HPA axis], thyroid [hypothalamus-pituitary-thyroid (HPT) axis], or gonads [hypothalamus-pituitary-gonad (HPG) axis]. They exert regulatory effects on the immune system, and any imbalance disrupting such neuroimmunoendocrine communication may result in pathological conditions (1-3). 
Among the cells of the immune system involved in neuroendocrine interactions, macrophages play a central role in the activation and modulation of both innate and adaptive immune responses. Interestingly, an intricate bidirectional macrophageneuroendocrine system crosstalk is currently being explored to understand homeostasis and diseases. Here, we review how macrophages bridge the immune, endocrine, and nervous systems, how hormones and neurotransmitters may influence their physiology and function and to what extent such circuitry may be placed as potential therapeutic targets in various diseases. We do not extend our analysis on how macrophage-derived mediators affect brain activity and behavior, since recent comprehensive reviews about this issue have been published (4-6).

\section{MACROPHAGES AND NEUROENDOCRINE COMPONENTS}

Macrophages are multifunctional leukocytes that recognize and remove invading pathogens, toxins, cellular debris and apoptotic cells in healthy or inflamed tissues. They are tissue-resident cells that have settled during embryogenesis or monocyte-derived cells that migrated from the blood circulation and reached different organs (7). Depending on the organ they populate, macrophages receive different designations, which are supported by specific differentiation programs, cell morphologies, and specialized functions $(8,9)$. To name a few, they are known as microglia in the brain, alveolar macrophages in the lungs, Kupffer cells in the liver, osteoclasts in bones, and chondroclasts in cartilages. More specifically, macrophages are further classified into distinct subpopulations based on their functional properties, which may comprise non-activated circulating monocytes, pro-inflammatory or anti-inflammatory macrophages, among others. Indeed, strong plasticity in their differentiation and the notion that these subsets may be interchangeable have led to the proposition of a "spectrum wheel" system (10-12). In this regard, additional cellular subsets can be defined by a combination of characteristics, as it will be discussed below.

To perform their roles, macrophages rely on a wide range of specific surface and intracellular receptors. These sensors are able to recognize microbial components, defined as pathogen-associated molecular patterns, and danger molecules released after cell and tissue lesions, defined as damage-associated molecular patterns. Macrophages activated through these receptors produce potent pro-inflammatory cytokines, such as TNF- $\alpha$, IL- $1 \beta$, IL- 6 , and IL-12, together with chemokines and toxic-free radicals (13-15). Furthermore, other receptors play critical roles on macrophage function. For example, scavenger receptors (SRs) bind a diverse range of ligands from bacteria to native proteins, allowing them to regulate both cell adhesion and removal of noxious agents by phagocytosis (16). A class of SRs includes the mannose receptor (CD206), which is a marker of M2 macrophages (see below). In fact, when CD206-positive macrophages were eliminated from the lungs of a murine transgenic model of toxemia by the administration of diphtheria toxin, mice developed an exacerbated lung inflammation upon endotoxin challenge (17). Death of neighboring cells by apoptosis is initially perceived by macrophages through specific receptors that recognize phosphatidylserine exposure in the lipid bilayer membrane of dying cells. Macrophages are also able to detect complement molecules through cognate receptors and antibodies through Fc receptors. These molecules opsonize pathogens and abnormal cells, thus stimulating their phagocytosis.

Analyses of a large body of evidence revealed that macrophages could respond to a wide variety of neuroendocrine factors [e.g., Ref. (18)]. In particular, a second-level evaluation of published data sets available through the Immunological Genome Project (ImmGen) Consortium (19) shows that monocytes and macrophages express not only numerous hormone and neurotransmitter receptors (Figure 1) but also a number of the corresponding cognate ligands. More specifically, using neuroendocrine-related gene expression profiles, it is possible to cluster myeloid cells by cell type and body locations (Figure S1 in Supplementary Material). Accordingly, the genes for angiotensin I converting enzyme (Ace), 15-hydroxyprostaglandin dehydrogenase $(H p g d)$, and EGF-like module containing, mucin-like, hormone receptor-like sequence 4 (Emr4/Adgre4) are highly expressed in different populations of circulating monocytes. Contrasting with this transcriptomic observation, Stacey et al. (20) have identified higher expression levels of Emr4/Adgre4 predominantly in resident macrophages. In a second hand, genes such as Ltc4s, Ptgs1, Igf1, Ophn1, Hpgds, Gatm, Pgcp, and Cysltr1 were highly expressed in most macrophages and some populations of dendritic cells, but slightly expressed in monocytes. Together, the presence of neuroendocrine components in monocytes and macrophages provide the grounds for the notion that macrophage-neuroendocrine crosstalk influences the overall homeostasis and immunity of an individual.

In the sections below, we will discuss in more detail how hormones, nervous-derived cytokines, and neurotransmitters regulate different aspects of macrophage biology related to the preservation of internal homeostasis.

\section{NEUROTRANSMITTERS AND HORMONES REGULATE MACROPHAGE FUNCTION}

The vast number of neuroendocrine factors places a significant challenge for the quest to unravel brain-immune communication. Nevertheless, it may also unveil numerous possibilities for clinical intervention. The early isolation of specific hormones and the availability of recombinant proteins, as well as gene editing technologies, have allowed the study of various molecules of interest in macrophage physiology. The first studies showing that macrophages were able to respond to neurotransmitters date back to mid-past century with the finding that phagocytosis was stimulated by histamine (21). This small monoamine messenger is produced by some immune cells (e.g., mast cells and basophils) and by neurons of the tuberomammillary nucleus of the hypothalamus $(22,23)$. The biological significance of histamine to macrophage function was later demonstrated in distinct models of intracellular infection (24-26) and paved the way for the investigation of other neurotransmitters endowed with similar properties to modulate macrophage physiology.

The discovery that macrophages also respond to hormonal stimuli came shortly after. Then, a large body of publications 


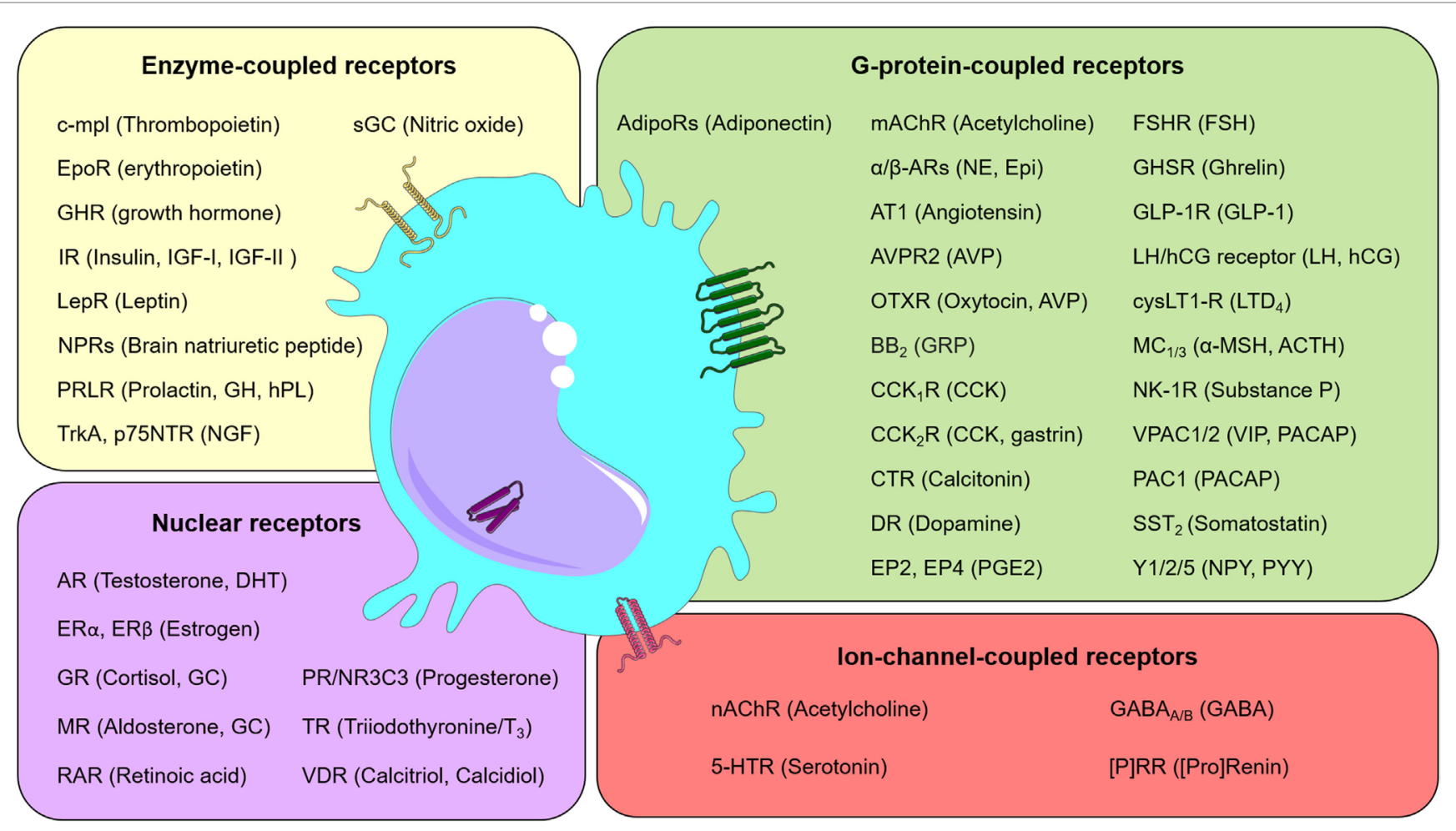

FIGURE 1 | Neuroendocrine communication on macrophages. Schematic representation listing selected receptors (and their ligands) found in macrophages. Receptors were grouped into classes, as indicated. Abbreviations: (P)RR, (pro)renin receptor; 5-HTR, serotonin receptor; ACTH, adrenocorticotropic hormone; AdipoRs, adiponectin receptors; AR, androgen receptor; AT1, angiotensin II receptor type 1; AVP, arginine vasopressin or antidiuretic hormone; AVPR2, arginine vasopressin receptor 2; BB2, bombesin receptor; CCK, cholecystokinin; CCK $1 / 2 \mathrm{R}$, cholecystokinin receptor 1/2, respectively; c-mpl, myeloproliferative leukemia protein; CO, carbon monoxide; CTR, calcitonin receptor; cysLT1-R, cysteinyl leukotriene receptor 1; DHT, dihydrotestosterone; DR, dopamine receptor; EP2, prostaglandin E2 receptor 2; EP4, prostaglandin E2 receptor 4; Epi, epinephrine; EpoR, erythropoietin receptor; ER, estrogen receptor; FSH, follicle-stimulating

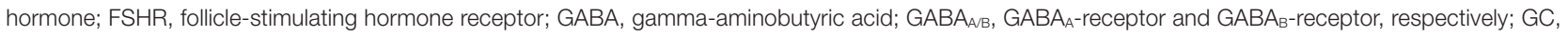
glucocorticoids; GH, growth hormone; GHR, growth hormone receptor; GHSR, growth hormone secretagogue receptor (also known as ghrelin receptor); GLP-1, glucagon-like peptide-1; GLP-1R, Glucagon-like peptide-1 receptor; GR, glucocorticoid receptor; GRP, gastrin-releasing peptide; hCG, human chorionic gonadotropin; hPL, human placental lactogen; IGF, insulin-like growth factor; IR, insulin receptor; LepR, leptin receptor; LH, luteinizing hormone; LTD, leukotriene $\mathrm{D}_{4}$; $\mathrm{mAChR}$, muscarinic acetylcholine receptor; $\mathrm{MC}_{1 / 3}$, melanocortin 1/3 receptor, respectively; MR, mineralocorticoid receptor; $\mathrm{nAChR}$, nicotinic acetylcholine receptor; NE, norepinephrine; NGF, nerve growth factor; NK-1R, neurokinin 1 receptor; NPRs, natriuretic peptide receptors; NPY, neuropeptide Y; NR3C3, nuclear receptor subfamily 3, group C, member 3; OTXR, oxytocin receptor; p75NTR, neurotrophin receptor p75; PAC1, pituitary adenylate cyclaseactivating polypeptide type I receptor; PACAP, pituitary adenylate cyclase-activating peptide; PGE2, prostaglandin 2; PR, progesterone receptor; PRLR, prolactin receptor; PYY, Peptide YY; RAR, retinoic acid receptor; SGC, soluble guanylyl cyclase; Soluble guanylyl cyclase (GC-1); SST 2 , somatostatin receptor type 2; TR, thyroid hormone receptor; TrkA, transmembrane tyrosine kinase; VDR, vitamin D receptor; VIP, vasoactive intestinal peptide; VPAC1/2, vasoactive intestinal peptide receptor $1 / 2$, respectively; $Y 1 / 2 / 5$, neuropeptide $\mathrm{Y}$ receptor type $1 / 2 / 5$, respectively; $\alpha / \beta$-ARs, $\alpha / \beta$-adrenergic receptors; $\alpha$-MSH, melanocyte-stimulating hormone.

showed that hormones can broadly modulate both the immune system and inflammatory responses [e.g., Ref. (27-31)]. Among them, early clinical observations and experimental investigations provided evidence that the formation of the so-called granulation tissue was impaired upon treatment with cortisone or adrenocorticotropic hormone (ACTH) $(29,32)$. The absence of this delimited transitory regenerative response full of macrophages and new blood vessels raised the assumption that corticosteroids could weaken macrophage function, a hypothesis that was later undermined by the finding that corticosteroids were shown to promote macrophage migration in culture $(33,34)$. Indeed, the effects of corticosteroids on the formation of granulation tissue seem to rely on suppressing blood vessel formation through the inhibition of platelet-derived growth factor-dependent expression of vascular endothelial growth factor (35). Since those discoveries, reports concerning neuroendocrine modulation of the immune system have become available, and many comprehensive reviews have been published $(36,37)$. Therefore, herein, we will focus on the influence of neuroendocrine messengers on macrophage physiology by dividing the distinct stages of their lifespan into the following sub-sections.

\section{Monocyte/Macrophage Maturation May Be Driven by Neuroendocrine Components}

Although macrophage origin remains a matter of intense debate, they seem to arise from at least two distinct locations. Early in 
life, $M y b$-independent yolk sac-derived erythro-myeloid Csf1rpositive progenitors emerge from blood islands, colonize the developing liver at early- to mid-gestation, and subsequently reach other organs, such as lungs, epidermis, and brain (9, 38-43). These macrophages can persist and proliferate in either healthy young adults or upon tissue insult (40, 44-46). Later, new macrophages and dendritic cells differentiate from bone marrow-derived circulating monocytes upon reaching a target tissue damaged by inflammatory reactions or pathogens.

The influence of neuroendocrine messengers on early macrophage differentiation is largely underappreciated, but a closer look at the data published by Mass et al. (9) reveals that many neuroendocrine-related genes are differentially expressed during macrophage stepwise maturation (Figure 2). Some of them, like calcitonin-related genes (Calcrl and Ramp2), prostaglandinassociated genes (Ptgis and Ptger4), and both Vipr2 and Ghr are highly expressed in erythro-myeloid progenitors (EMPs), but gradually decline as cells differentiate into macrophages. The glutamate receptor gene Gria3 exhibits high expression levels in EMPs, a further increase in $\mathrm{CD}_{4} 5^{+} \mathrm{Kit}^{-} \mathrm{Lin}^{-}$pre-macrophages (pMacs), and a subsequent reduction in mature macrophages. In turn, the erythropoietin receptor gene (Epor) is detected in intermediate levels either in EMPs or macrophages, but it shows a low expression in pMacs. Other genes, such as Adbr2 ( $\beta 2-$ adrenergic receptor), Ednrb (endothelin receptor type B), and Igf1 (insulin-like growth factor 1), exhibit lower levels in EMPs and pMacs, but higher expression in macrophages. Together, these expression profiles suggest that neuroendocrine signals modulate macrophage maturation and may affect macrophage function. Experimental investigations using selective activation or inactivation of genes of interest in conditional systems are, therefore, necessary to elucidate possible medical benefits from manipulating neuroendocrine influence on macrophage differentiation.

\section{Macrophage Polarization in Response to Neuroendocrine Stimuli}

It is acknowledged that it is through cell polarization that proper macrophage effector responses can be achieved in target tissues. However, macrophage nomenclature may be confusing to reconcile between in vitro-induced phenotypes and their in vivo relevance. From now on, we will refer to macrophage subsets based on their functions or cellular markers, thus avoiding whenever possible the misconceptions that may arise from distinct stimulation conditions among laboratories (47).

The preference toward a given functional phenotype of macrophages is classically triggered by cytokines and specific pathogens. Formerly known as M1 or classically activated macrophages, cells involved in host defense against microbes and tumors show a pro-inflammatory phenotype induced by IL-12 and IFN- $\gamma$ [M(IFN $\gamma)$ macrophages]. Interestingly, they also participate in the onset of tissue repair upon an injury or trauma $(47,48)$. In turn, a heterogeneous population of anti-inflammatory macrophages may arise secondary to stimulation with Th2 cytokines, glucocorticoids, immune complexes, colony stimulating factor-1, or by some intracellular microorganisms, such as Leishmania $(49,50)$. Initially associated with wound healing and known

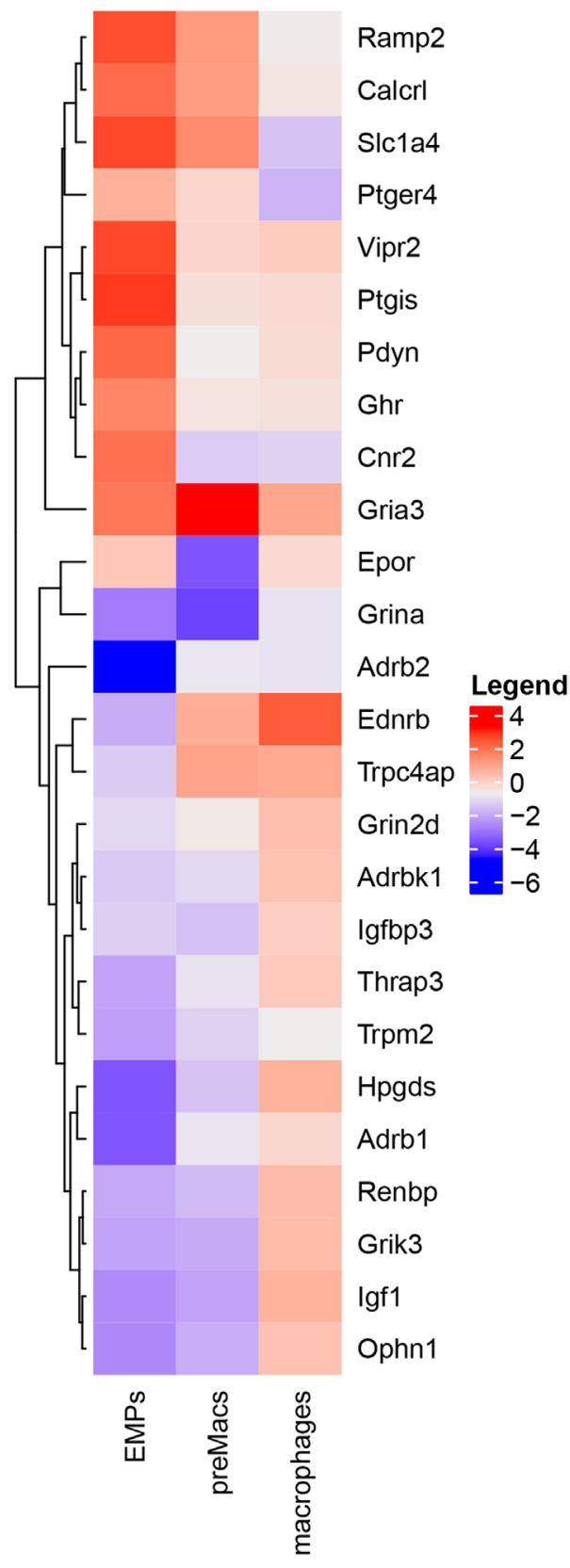

FIGURE 2 | Neuroendocrine-associated genes are differentially expressed during macrophage differentiation. Heatmap of RNA-Seq profile filtered by keywords from Mass et al. (9) depicting hierarchically clustered relative gene expression (log2) in erythro-myeloid progenitors, pre-macrophages (preMacs), and macrophages. Levels of expression are represented by colors in which red, white, and blue indicate high, intermediate, and low intensities, respectively.

as alternatively activated or M2 macrophages, these antiinflammatory cells show increased arginase-1 activity, which generates ornithine and urea. Ornithine is subsequently converted to proline and polyamines, which are used in the biosynthesis of collagen and in cell proliferation, respectively $(51,52)$. By converting arginine to ornithine, arginase- 1 competes with the nitric oxide (NO)-producing enzyme NO synthase characteristic 
of pro-inflammatory macrophages (53). Other anti-inflammatory macrophages may be produced by the incubation with IL-10 $[\mathrm{M}(\mathrm{IL}-10)]$ or glucocorticoids and TGF- $\beta[\mathrm{M}(\mathrm{GC}+\mathrm{TGF} \beta)]$, thereby polarizing them to a pro-healing phenotype with high scavenging activity also known as "deactivated, regulatory, or M2c macrophages" [reviewed by Martinez et al. (54)]. Unlike M(IFN $\gamma)$, M(IL-4), or M(IL-10) macrophages, glucocorticoidinduced macrophages express higher levels of Mer tyrosine kinase (MerTK), a surface receptor involved in the phagocytosis of early apoptotic cells through the recognition of exposed phosphatidylserine (55). Despite their specificities, these phenotypes are plastic, and macrophages can switch between distinct functions both in vivo and in vitro upon a number of distinct stimuli (10-12, 56-58).

The finding that glucocorticoids influence macrophage polarization points out that neuroendocrine components may also contribute to macrophage subset decision and hence tissue regeneration. In this regard, Gratchev et al. (59) have demonstrated that $\mathrm{M}(\mathrm{IL}-4)$ macrophages secrete extracellular matrix (ECM) components and remodeling enzymes, as tenascin- $\mathrm{C}$ and metalloproteases, respectively, whereas $\mathrm{M}(\mathrm{GC})$ macrophages exhibited undetected or reduced levels of many ECM-associated proteins. Of note, cell-specific gene inactivation of the mouse glucocorticoid receptor (GR) in the myeloid lineage impaired cardiac healing after experimental ischemic injury, due to abnormal collagen scar formation, reduced neovascularization, and persistent pro-inflammatory differentiation of macrophages. Moreover, dexamethasone can overcome the effects of IL-4 on the production of macrophage-derived ECM molecules. Unlike M(IL-4) cells, only M(IL-4 + dexa) or M(GC) macrophages were responsive to TGF- $\beta$, a major cytokine in the resolution phase (Figure 3) (60). Thereby, dexamethasone modulates the resolution phase by inhibiting the expression of NF- $\mathrm{BB}$-dependent pro-inflammatory cytokines involved in the initial dominant inflammatory phase while inducing a resolutive and reparative phenotype (61-64). This limits inflammation and highlights the preponderant role of glucocorticoids on the regulation of macrophage function.

The modulatory properties of neurotrophic factors and neuropeptides are also prominent in the regulation of immune cells, including monocytes and macrophages. For instance, norepinephrine by itself is a potent inducer of alternatively activated macrophages even in the presence of LPS (65). By contrast, activation of monocytes and macrophages by LPS induces increased

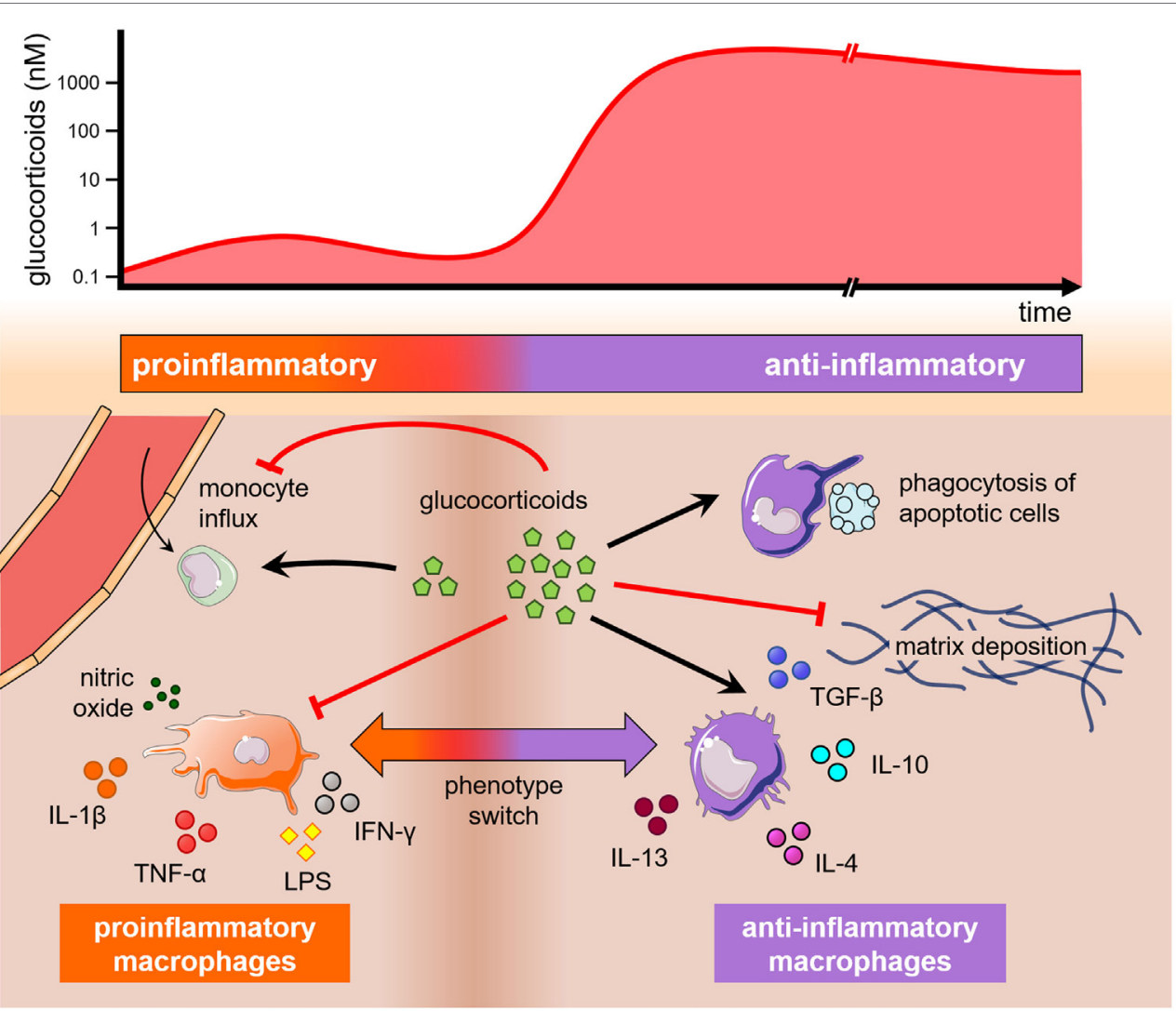

FIGURE 3 | The influence of glucocorticoids on monocytes and macrophages. Glucocorticoids may play opposing effects on monocytes and macrophages depending on theirs levels and time of exposure (top). A graphical representation depicts these effects on monocyte trafficking into tissues, macrophage polarization, and phagocytosis (bottom). A short and low increase in glucocorticoid levels (left) stimulates monocyte extravasation into the injured tissue, while high and long-lasting levels of glucocorticoids (right) inhibit monocyte proliferation and extravasation, as well as drive macrophage polarization into anti-inflammatory phenotypes that may produce extracellular matrix or stimulate the engulfment of apoptotic cells. All these phenomena are also influenced by cytokines present in the milieu. 
production of the neurotrophin nerve growth factor (NGF), which favors a pro-inflammatory phenotype through the induction of monocytecytotoxicpotentialand the production of TNF- $\alpha(66,67)$. Importantly, macrophage production of NGF protects them against apoptosis during inflammation or HIV-1 infection $(67,68)$. However, the protective survival role of NGF in HIV-1-infected macrophages may be counterbalanced by its stimulating effect on viral replication, which occurs through the downregulation of the cytidine deaminase APOBEC3G (69). Neurotrophins may actually play opposing roles in their abilities to control the growth of pathogens in macrophages, since NGF protects macrophage from infection with the protozoan Leishmania donovani through the increased production of hydrogen peroxide (70). Meanwhile, the widely distributed vasoactive intestinal peptide and the pituitary adenylate cyclase-activating polypeptide (PACAP) downregulate macrophage-derived production of numerous pro-inflammatory molecules, whereas inducing macrophage synthesis of the anti-inflammatory mediators IL-4 and IL-10 (71-73). Overall, neuropeptides are able to modulate macrophage-dependent activities and promote body homeostasis in conditions as diverse as recovering injured nerve tissue, restraining tumor progression or preventing HIV-1 production $(72,74,75)$.

\section{Modulation of Macrophage Migration by Hormones and Neurotransmitters}

The movement of cells is central for proper physiology. During macrophage ontogeny in adults, progenitor cells leave the bone marrow-associated hematopoietic stem cell niche and reach the bloodstream, where they can travel to distant parts of the body. Upon any insult, circulating monocytes are recruited to different tissues by specific chemotactic factors, such as CC- and $\mathrm{CX}_{3} \mathrm{C}$ chemokine ligands. The receptors of these chemotactic factors also contribute to defining specific monocyte subsets. In humans, classical monocytes are defined by high expression levels of the LPS co-receptor CD14 and the absence of the Fc $\gamma$ receptor CD16, while expressing high levels of the CC-chemokine receptor 2 (CCR2) and low levels of the $\mathrm{CX}_{3} \mathrm{C}$-chemokine receptor 1 $\left(\mathrm{CX}_{3} \mathrm{CR} 1\right)$. In turn, $\mathrm{CD}_{16^{+}}$monocytes can be further divided into two groups, both expressing high levels of $\mathrm{CX}_{3} \mathrm{CR} 1$ and low levels of CCR2. Non-classical cells are $\mathrm{CD} 14^{\mathrm{lo}} \mathrm{CD} 16^{\mathrm{hi}}$, whereas intermediate cells are $\mathrm{CD} 14^{\mathrm{hi}} \mathrm{CD} 16^{\mathrm{lo}}(76)$. In this regard, several studies have reported that both hormones and neurotransmitters can modulate monocyte or macrophage migration by tuning the levels of target tissue-derived chemokines or the expression of their corresponding receptors (77-79). This lends an additional level of complexity to the control of macrophage behavior in health and disease.

One of these mechanisms includes the $\alpha 7$ and $\alpha 9$-nicotinic acetylcholine receptor ( $\mathrm{nAChR}$ )-mediated downregulation of CCL2 expression in the brain of the experimental autoimmune encephalomyelitis (EAE) mouse model of multiple sclerosis treated with nicotine. The inhibition of brain-derived CCL2 by nicotine impaired the recruitment of pro-inflammatory CCR $2^{+}$Ly $6 C^{\text {hi }}$ monocytes during murine EAE-which play a role similar to that of human classical CD $14^{+} \mathrm{CD} 16^{-}$monocytes-and could be an alternative for mitigating neuroinflammation in clinical settings
(80). In addition, the nAChR-dependent modulation of CCL2 expression may also contribute to treating genetic disorders, such as the Duchenne muscular dystrophy (DMD). This dystrophinrelated, X-linked condition is worsened by persistent muscle inflammation, including the respiratory muscles, which can cause patient death. A study using $m d x$ mice as a model of DMD found that the deficiency of CCR2 lowered the number of muscleinfiltrating inflammatory monocytes and macrophages, therefore, ameliorating disease severity and improving muscle strength (81). Together, this evidence suggests that modulating the migration of monocytes and macrophages through neuroendocrine components may be a valuable tool to control inflammatory diseases.

\section{STRESS-ASSOCIATED NEUROENDOCRINE MEDIATORS REGULATE MACROPHAGE PHYSIOLOGY}

A definition of stress can be troublesome, but usually involves an uncontrolled response of the body to aversive changes that may lead to anxiety, emotional tension, or fear. At the cellular level; however, stress is the result of ACTH release by the pituitary followed by the discharge of glucocorticoids produced by the adrenal cortex, along with the release of norepinephrine and epinephrine by the sympathetic-adrenomedullary (SAM) axis of the autonomic nervous system and the adrenal medulla, respectively (82). Glucocorticoids bind their nuclear GR through a mechanism dependent on GR-interacting protein-1 (GRIP1) phosphorylation by cyclin-dependent kinase-9 (83). Activation of this pathway leads to a broad repression of inflammatoryassociated genes regulated by the transcription factors NF- $\mathrm{BB}$ and $\mathrm{AP} 1$, and an upregulation of anti-inflammatory genes, such as the NF- $\kappa \mathrm{B}$ repressor glucocorticoid-induced leucine zipper (Gilz) $(61-63,84)$. In turn, signaling by norepinephrine and epinephrine relies on their interaction with $\beta 2$-adrenergic receptors ( $\beta 2$-ARs), which are seven-pass transmembrane receptors of the family of G-protein coupled receptors. Upon ligand binding-triggered conformational changes, they couple heterotrimeric $\mathrm{G}_{\mathrm{s}}$ proteins that relay signals to adenylyl cyclase for the production of cyclic AMP (cAMP) and subsequent activation of protein kinase $\mathrm{A}$ that may translocate to the nucleus and activate cAMP response element-binding protein to ultimately alter the transcription of target genes $(85,86)$. When any imbalance disrupting such neuroimmunoendocrine communication occurs, individuals are prone to immunosuppression and increased susceptibility to disease. This is a common occurrence nowadays due to the high number of people living under stressful conditions (87).

It is well established that stress-related mediators vastly affect monocytes and tissue-resident macrophages. For instance, the continued administration of glucocorticoids increases the number of monocytes in the periphery and within the bone marrow, while inducing a substantial reduction of the lymphoid population $(88,89)$. In culture, however, glucocorticoids were previously known to suppress macrophage growth (90). This apparent discrepancy is found in other monocyte/macrophage processes, such as monocyte trafficking. In fact, Rinehart et al. 
(91) observed that hydrocortisone succinate impaired the migration of human monocytes in culture, whereas other studies showed that glucocorticoids might stimulate monocyte migration by transiently increasing CCR2 expression in response to moderate physical exercise or transient stress $(92,93)$. These findings and many others support the notion that drastic changes in glucocorticoid pharmacological activity may occur as their levels and time of exposure increase. Thus, a brief and low-level exposure to glucocorticoids seems to prepare the tissue environment for a greater inflammatory cell response in case of a subsequent insult, whereas sustained high levels of glucocorticoids produce their well known anti-inflammatory properties (Figure 3) (93).

Stressors such as prolonged restraining, cold or heat exposure, footshocks, opioid administration, or psychological challenges disturb macrophage phagocytosis in mice (94-97). In general, these conditions activate both the HPA and SAM axes, while diminishing the levels of pro-inflammatory cytokines $(98,99)$. For example, cold-induced stress impaired the engulfment of apoptotic thymocytes by LPS-activated macrophages through a glucocorticoid-dependent mechanism that was accompanied by an increase in IL-10 levels. By contrast, treatment of INF$\gamma$-activated macrophages $[\mathrm{M}(\mathrm{IFN} \gamma)]$ with glucocorticoids enhanced Fc-mediated phagocytosis of sheep red blood cells in culture (100), thus revealing that the cellular context plays a critical role in macrophage responses. A rise of epinephrine and norepinephrine plasma levels also followed the acute cold stress, but these catecholamines seemed to have no influence on phagocytosis (96). Yet, these findings are at odds with other observations. In particular, many studies have shown that treatments with corticosterone or the glucocorticoid analogs methylprednisolone, dexamethasone, or hydrocortisone augmented macrophage phagocytosis $(59,101)$, an outcome that was not observed for the mineralocorticoid aldosterone or the sex steroids estradiol or progesterone (102). Taken together, the available information points out that the local or systemic release of stress hormones modulates macrophage ability to phagocytose and may exert a significant impact on both innate and adaptive responses, since the engulfment of apoptotic cells leads to the upregulation of anti-inflammatory genes and cytokines by macrophages (103-105).

Upon phagocytosis, macrophages process and present antigens through MHC molecules to T cells, which might differentiate into unique subsets, such as Th1, Th2, and Th17, each of them bearing specific functions. Stressful conditions may affect macrophage antigen presentation and modify the Th1/ Th2/Th17 balance by altering the macrophage cytokine profile and thereby increasing susceptibility to infections or allergic processes (2). For instance, a 4-day exposure of mice to cold water lowered the IFN- $\gamma$-induced expression of MHC class II molecules in macrophages (106). Similar findings were observed in restrained mice, in which macrophages showed reduced levels of MHC class II and upregulated concentrations of plasma corticosteroids $(107,108)$. A rise of serum glucocorticoids and a concomitant decrease in the production of NO through the activation of the HPA axis upon acute cold-induced stress result in the development of an immunosuppressive response that is enhanced by norepinephrine-producing fat-resident macrophages (109-111). Likewise, a Th2-immune response could be observed in heat-stressed mice, which exhibited high plasma levels of norepinephrine and increased macrophage production of CCL2, whose synthesis was controlled by norepinephrine depletion (112). Glucocorticoids, norepinephrine, and epinephrine were able to favor a Th2 profile because they inhibited macrophage synthesis of IL-12, a major Th1-inducing molecule $(65,113)$. Similarly, corticosteroid-treated monocytes lose their capacity of inducing the production of IFN- $\gamma$ by $\mathrm{CD}^{+} \mathrm{T}$ lymphocytes, whereas stimulating their secretion of IL-4 (114). In addition, stress caused by electric shocks raised plasma corticosterone levels and lowered macrophage antitumor activity, favoring the growth of Ehrlich ascites tumor in a mouse model (95). Other forms of stress induction, such as restraining or corticosterone injection, inhibited the production of TNF- $\alpha$ and reactive nitrogen species by macrophages, which thereby increased susceptibility to Mycobacterium avium infection (115).

As part of the HPA axis, there is also an acetylcholine-based suppressive neuroinflammatory-macrophage communication that is centered on the stimulation of the vagus nerve by microorganisms or cytokines (116). Anatomically, these paired nerves gather long-range afferents that convey systemic behavior-changing signals into the brain, and efferents from the medulla oblongata that innervate the heart and numerous visceral organs. In organs such as the liver, pancreas, and the gastrointestinal tract, these nervous fibers can exert relevant control of metabolism and tissue homeostasis (116-118). The release of acetylcholine from synaptic nerve endings targets both muscarinic and nicotinic acetylcholine receptors ( $\mathrm{mAChR}$ and $\mathrm{nAChR}$, respectively), whose subunits are differentially expressed by monocytes and macrophages depending on species, maturation stage, tissue, and degree of cell activation (119-124). Interaction of the vagus nerve with tissue-resident macrophages is not always direct; in the gut, there is the participation of intervening myenteric neurons scattered around the muscularis layer, whereas the spleen shows no evidence of vagal innervation (125).

Stimulation with acetylcholine inhibits mortality associated with the LPS-induced production of macrophage pro-inflammatory cytokines, such as IL-1 $\beta$, IL- 6 , and TNF- $\alpha$, whereas injuries of the vagus nerve may culminate in uncontrolled inflammatory responses (126). In BALB/c mice, vagotomy led to Kupffer celldependent fulminant hepatitis upon intraperitoneal co-injection of LPS and D-galactosamine, an effect that was either reduced by nicotine or exacerbated by $\alpha$-bungarotoxin, a selective antagonist of the nAChR $\alpha 7$ subunit (127). In agreement with these observations, agonist binding to the $\mathrm{nAChR} \alpha 7$ subunit induced the Jak2/STAT3 pathway to suppress resident peritoneal macrophage activation and inflammation (128). Actually, each of these signaling components may have clinical standing to ameliorate the inflammatory output. Notwithstanding, electrical stimulation of the vagus nerve through non-invasive devices is a likely alternative to reduce the numbers of drug-based interventions, as experimentally demonstrated in inflammatory bowel disease, kidney ischemia-reperfusion injury, and rheumatoid arthritis 
(129-131). Thus, the intricate neuroendocrine regulatory mechanisms of macrophages pose a challenge, but support a role for hormone and neurotransmitter receptors as amenable targets for the development of effective therapeutic strategies based on regulating monocyte and macrophage differentiation, migration, polarization and activation, phagocytosis, or antigen presentation.

\section{TISSUE-SPECIFIC DIFFERENCES IN MACROPHAGE REGULATION BY STRESS MEDIATORS}

Glucocorticoids effects on macrophages generally influence the resolution phase of inflammation. Interestingly, their actions can be regulated locally by cell-specific particularities, such as receptor availability and metabolism. One of these mechanisms includes the enzymes $11 \beta$-hydroxysteroid dehydrogenases type 1 (11 $\beta$-HSD 1$)$ and type $2(11 \beta$-HSD2) that act upstream of the GR receptor and are ultimately responsible for glucocorticoid metabolism. In general, they play opposing roles in a tissuedependent context. Whereas $11 \beta$-HSD1 converts inactive cortisone to active cortisol in the vasculature, adipose tissue, muscle, liver, and brain, the $11 \beta$-HSD2 enzyme inactivates cortisol to cortisone in the kidneys and colon. Thereby, glucocorticoid levels can be controlled independently from the systemic axis [reviewed by Chapman et al. (132)].

Macrophages also differentially express these enzymes. In particular, the expression of $11 \beta-H S D 2$ is low, whereas the levels of $11 \beta$-HSD1 are highest in anti-inflammatory macrophages and high in pro-inflammatory cells when compared to resting macrophages $(133,134)$. This occurs because the cytokines IL- 4 or IL-13 are able to upregulate $11 \beta$-HSD 1 activity, whereas IFN- $\gamma$ plays a suppressive role. A higher expression of $11 \beta-H S D 1$ is also found as monocytes differentiate to anti-inflammatory macrophages. Incubation with LPS produces no alteration on the expression of $11 \beta$-HSD1 in monocytes, but it can increase enzyme levels in pro-inflammatory macrophages (133). In microglia, LPS does induce an upregulation of $11 \beta$-HSD1 expression, but without an apparent change in protein abundance (135). Likewise, the same stressor may also initiate opposing responses in macrophages, which may result in confusion or difficulty of interpretation. For instance, acute cold stress induces a reduction in the phagocytic activity of resting macrophages that is mediated by corticosterone, but an increase in phagocytosis by activated cells that depends on catecholamines (136). On the other hand, chronic cold stress promotes an anti-inflammatory phenotype that correlates with increased expression of $11 \beta-H S D 1$ (137). In the adipose tissue, these anti-inflammatory macrophages secrete catecholamines to induce thermogenic gene expression in brown adipose tissue and lipolysis in white adipose tissue (111). In turn, neuron-produced norepinephrine activates tissue-protective programs by muscularis macrophages in the intestine, whereas lamina propria macrophages exhibit pro-inflammatory characteristics (138). Those muscularis macrophages respond similarly to norepinephrine as the microglia in the CNS $(139,140)$.

Together, these observations point out that tissue-specific macrophages have the ability to respond differently to the same neuroendocrine stimulus such as glucocorticoids, and it suggests the existence of an intricate tissue-dependent network of regulation on macrophage function. A pathological condition can, however, modify macrophage response to neuroendocrine mediators. Similar to alveolar macrophages in acute respiratory distress syndrome, synovial macrophages in osteoarthritis or rheumatoid arthritis present high levels of $11 \beta$-HSD2, which may contribute to glucocorticoid resistance and the persistence of chronic inflammation (141-143).

\section{CLINICAL RELEVANCE OF TARGETING MACROPHAGES WITH NEUROENDOCRINE SIGNALS}

Both neurons and immune cells are able to sense and respond to exogenous and endogenous challenges, being involved in governing critical homeostatic pathways. It is a remarkable feature the existence of a network allowing these cells to interact with each other via cell-cell communication or via their main soluble signaling molecules, the neurotransmitters, and cytokines. Considering that these bidirectional communications may be disturbed in immunopathological and neurological diseases, the better understanding of such an intricate body of interactions may help to both unveil new mechanisms of diseases and the search for new therapies. An important homeostatic arm to counteract an inflammatory state is driven by the nervous system via triggering the HPA axis and the consequent release of glucocorticoids, and also by activating the sympathetic nervous system to secrete catecholamines. As target cells of these factors, macrophages can be turned to an anti-inflammatory state as glucocorticoids are regarded by their immunosuppressive function and the catecholamines can induce IL-10 macrophage secretion (Figure 3) $(65,144)$. Additionally, macrophages seem to be regulated by the efferent vagus nerve via their nicotinic acetylcholine receptors (145). Therefore, aiming at controlling undesired effects of tissue inflammation, one can envisage that interfering on brain-to-macrophage signaling might be an effective strategy to induce regulatory therapies for inflammatory diseases.

In a second hand, the differentiation program of monocyte/ macrophage lineages, and their functional activities, following the differentially acquired polarization status, show a more complex pathway for exploring therapeutically the macrophage to brain signaling. Nonetheless, several studies have demonstrated the critical role of monocyte/macrophage recruitment, activation and polarization in tissue injury and in the outcome of disease progression. Indeed, a change in macrophage function is critical at the distinct phases necessary for the restoration of tissue homeostasis. During the regeneration of skeletal muscle, for example, pro-inflammatory monocyte-derived macrophages induce the proliferation and migration of progenitor myoblasts at the injury site $(146,147)$. The phagocytosis of dying cells then induces a switch of proinflammatory macrophages to an anti-inflammatory phenotype that stimulates myoblast fusion and both the repair of damaged muscle fibers and the formation of new ones $(148,149)$. 
The concerted activity of both pro- and anti-inflammatory subsets restores the contractile machinery of muscle fibers and repair the underneath fiber basement membrane. As a proofof-concept for the delivery of macrophages in clinical application, the coinjection of human myoblasts with pro-inflammatory human macrophages into cryodamaged tibialis anterior muscle of $\mathrm{Rag}^{-/-} \gamma \mathrm{C}^{-/-}$immunodeficient mice increased muscle cell proliferation and migration, whereas inflammatory cells transited to a resolutive phenotype that supported muscle differentiation through the production of TGF- $\beta$ after 5 days (146). On the other hand, blocking the anti-inflammatory tumor-promoting activity of tumor-associated macrophages has been reported as an encouraging antitumor therapy (150-152). Interestingly, this can be achieved by the administration of M(LPS + IFN- $\gamma$ ) macrophages in the affected area, which then recruit endogenous macrophages and instruct them into $\mathrm{Ly}_{6 \mathrm{C}} \mathrm{C}_{\mathrm{lo}} \mathrm{CD} 11 \mathrm{~b}^{\mathrm{hi}} \mathrm{F} 4 / 80^{+}$ restorative cells (153).

As for the CNS, one should take into account the broad presence of microglia, the CNS-specific resident macrophages. In this context, as the microglia faces potentially harmful invading entities (e.g., pathogens or tumors), these immunosurveillance cells become activated, triggering a protective inflammatory response. However, dysregulation of this neuroinflammation state might result in tissue damage and neurodegeneration, which show microglial activation as a central pathogenic hallmark (154). This concept points out that approaching microenvironmental polarization in the CNS should be well balanced. Nonetheless, the vast body of fundamental data and clinical studies also indicate that targeting macrophage/microglia activation and polarization should be pursued as a potential therapy for neuroinflammatory diseases. In fact, some clinical and experimental therapeutic approaches for neuroinflammatory conditions are known to induce an anti-inflammatory microenvironment in the CNS with increased expression of type- 2 cytokines. Such polarization seems to result in both immunosuppressive and regenerative effects, with the production of anti-inflammatory cytokines and neurotrophic factors, including TGF $\beta$, IL-10, IGF-1, and BDNF (155). Thus, experimental studies aiming at the generation of a Th2 and anti-inflammatory microenvironment by carrying IL-4 expression through viral vectors to the CNS in a murine model of multiple sclerosis, resulted in significant reduction in neuroinflammation and neurodegeneration [reviewed in Ref. (155)]. Similarly, the therapy with synthetic polypeptides that resemble myelin basic protein, known as glatiramer acetate, was reported to induce type-2 cytokines and BDNF production by immune cells, and play an immunomodulatory effect on the relapsing form of multiple sclerosis (156). Accordingly, the presence of anti-inflammatory (or immunosuppressive) macrophages reduces pro-inflammatory components and might offer support for neuronal survival. In fact, enhanced expression of BDNF has been described in activated macrophages and microglia following brain injury $(157,158)$. Also, a switch to an anti-inflammatory Arg $-1^{+} \mathrm{CD} 68^{+}$ phenotype in microglia and peripherally derived macrophages was shown to correlate with remyelination and to support oligodendrocyte differentiation in a murine model of CNS demyelination (159).
The complex nature of macrophage polarization also shows the potential role of $\mathrm{CD} 14^{+} \mathrm{CD} 16^{+} \mathrm{CD} 163^{+} \mathrm{CD} 204^{+} \mathrm{CD} 206^{+}$ $\mathrm{CD}^{209^{-}}$macrophages in the resolution of an inflammatory state. Anti-inflammatory M(M-CSF) or M(GC) macrophages highly express the MerTk receptor for apoptotic cells (55), a feature that points out this phenotype as a further target in neuroinflammatory conditions as the neuronal protection and survival requires an efficient clearance of apoptotic cells and debris. Engulfment of apoptotic cells by M(M-CSF + IL-10) macrophages integrates resolution of inflammation with proper tissue repair and the consequent waning of the neurodegeneration process (55).

The immunomodulatory role of the cholesterol-lowering drug atorvastatin on macrophage function has also been explored as a potential anti-neuroinflammatory agent. In a murine model of traumatic brain injury, this drug inhibited microglia/macrophage activation and showed enhanced antiinflammatory polarization (160). Interestingly, atorvastatin has been reported to downmodulate activation of a blood monocyte subset that seems to be involved in HIV-1-associated neurocognitive disorders (161). Since this compound can accumulate in the CNS, its effects on both recruited inflammatory monocytes and microglia have been a matter of clinical investigation (https://clinicaltrials.gov/, ID: NCT01600170). Altogether, these data gather some interesting concepts derived from basic studies regarding the regulation of macrophage activities on homeostatic and pathological conditions. More importantly, the evidence of macrophage interplay with components of the nervous system and their functional role in neuroinflammatory conditions mounts progressively, hopefully enticing new clinical studies on more efficient treatment of cancer, inflammatory and neurodegenerative diseases.

\section{AUTHOR CONTRIBUTIONS}

AJ conceived the review subject, analyzed transcriptome data, and wrote the paper. VC-d-A and JT wrote the paper. WS conceived the review subject and wrote the paper. DB-H and IR conceived the review subject, coordinated the work, and wrote the paper. Artwork by AJ and IR.

\section{ACKNOWLEDGMENTS}

The authors thank Dr. Rômulo Braga Areal for helpful discussions on data analysis. This work benefited from data assembled by Mass et al. (9) and the ImmGen consortium. Figures 1 and 3 were produced by modifying templates elaborated by Smart Servier Medical Art (https://smart.servier.com/, licensed under a Creative Commons Attribution 3.0 Unported License). AJ and JT are supported by the Rio de Janeiro State Research Council/FAPERJ (E-26/202.683/2016 and E-01/221169/2016, respectively). Our laboratory has been supported by grants from the Brazilian National Institute of Science and Technology on Neuroimmunomodulation/INCT-NIM, MERCOSUL Fund for Structural Convergence/FOCEM, the Brazilian Research Council/CNPq, and FAPERJ. This work is dedicated to the 
memory of an enthusiastic young scientist, Carlos Felipe Machado de Araújo.

\section{FUNDING}

$\mathrm{AJ}$ and JT are supported by the Rio de Janeiro State Research Council/FAPERJ (E-26/202.683/2016 and E-01/221169/2016, respectively). Our laboratory has been supported by grants from the Brazilian National Institute of Science and Technology on Neuroimmunomodulation/INCT-NIM, MERCOSUL Fund for Structural Convergence/FOCEM (03/11), the Brazilian Research Council/CNPq, and FAPERJ.

\section{REFERENCES}

1. Riley V. Psychoneuroendocrine influences on immunocompetence and neoplasia. Science (1981) 212(4499):1100-9. doi:10.1126/science.7233204

2. Calcagni E, Elenkov I. Stress system activity, innate and T helper cytokines, and susceptibility to immune-related diseases. Ann N Y Acad Sci (2006) 1069:62-76. doi:10.1196/annals.1351.006

3. Veiga-Fernandes H, Mucida D. Neuro-immune interactions at barrier surfaces. Cell (2016) 165(4):801-11. doi:10.1016/j.cell.2016.04.041

4. Galic MA, Riazi K, Pittman QJ. Cytokines and brain excitability. Front Neuroendocrinol (2012) 33(1):116-25. doi:10.1016/j.yfrne.2011.12.002

5. Lan X, Han X, Li Q, Yang Q, Wang J. Modulators of microglial activation and polarization after intracerebral haemorrhage. Nat Rev Neurol (2017) 13(7):420-33. doi:10.1038/nrneurol.2017.69

6. Werneburg S, Feinberg PA, Johnson KM, Schafer DP. A microglia-cytokine axis to modulate synaptic connectivity and function. Curr Opin Neurobiol (2017) 47:138-45. doi:10.1016/j.conb.2017.10.002

7. Ginhoux F, Guilliams M. Tissue-resident macrophage ontogeny and homeostasis. Immunity (2016) 44(3):439-49. doi:10.1016/j.immuni.2016.02.024

8. Okabe Y, Medzhitov R. Tissue-specific signals control reversible program of localization and functional polarization of macrophages. Cell (2014) 157(4):832-44. doi:10.1016/j.cell.2014.04.016

9. Mass E, Ballesteros I, Farlik M, Halbritter F, Günther P, Crozet L, et al. Specification of tissue-resident macrophages during organogenesis. Science (2016) 353(6304):aaf4238. doi:10.1126/science.aaf 4238

10. Mills CD, Kincaid K, Alt JM, Heilman MJ, Hill AM. M-1/M-2 macrophages and the Th1/Th2 paradigm. J Immunol (2000) 164(12):6166-73. doi:10.4049/ jimmunol.164.12.6166

11. Mosser DM, Edwards JP. Exploring the full spectrum of macrophage activation. Nat Rev Immunol (2008) 8(12):958-69. doi:10.1038/nri2448

12. Xue J, Schmidt SV, Sander J, Draffehn A, Krebs W, Quester I, et al. Transcriptome-based network analysis reveals a spectrum model of human macrophage activation. Immunity (2014) 40(2):274-88. doi:10.1016/j. immuni.2014.01.006

13. Duque GA, Descoteaux A. Macrophage cytokines: involvement in immunity and infectious diseases. Front Immunol (2014) 5:491. doi:10.3389/ fimmu.2014.00491

14. Kawasaki T, Kawai T. Toll-like receptor signaling pathways. Front Immunol (2014) 5:1-8. doi:10.3389/fimmu.2014.00461

15. Turner MD, Nedjai B, Hurst T, Pennington DJ. Cytokines and chemokines: at the crossroads of cell signalling and inflammatory disease. Biochim Biophys Acta (2014) 1843(11):2563-82. doi:10.1016/j.bbamcr.2014.05.014

16. PrabhuDas M, Bowdish D, Drickamer K, Febbraio M, Herz J, Kobzik L, et al. Standardizing scavenger receptor nomenclature. JImmunol (2014) 192(5):1997-2006. doi:10.4049/jimmunol.1490003

17. Kambara K, Ohashi W, Tomita K, Takashina M, Fujisaka S, Hayashi R, et al. In vivo depletion of CD206+ M2 macrophages exaggerates lung injury in endotoxemic mice. Am J Pathol (2015) 185(1):162-71. doi:10.1016/ j.ajpath.2014.09.005

18. Reyes-García MG, García-Tamayo F. A neurotransmitter system that regulates macrophage pro-inflammatory functions. J Neuroimmunol (2009) 216(1-2):20-31. doi:10.1016/j.jneuroim.2009.06.024

\section{SUPPLEMENTARY MATERIAL}

The Supplementary Material for this article can be found online at https://www.frontiersin.org/articles/10.3389/fimmu.2018.01440/ full\#supplementary-material.

FIGURE S1 | Monocytes and macrophages express many neuroendocrinerelated genes. Gene expression of selected neurotransmitters and hormone receptors (columns) in distinct monocyte and macrophage populations (rows) distributed throughout the body. The ImmGen dataset was plotted as heatmap with hierarchical clustering as described by Beyer et al. (162), using a coefficient of variation of $20 \%$. Levels of expression are represented by colors in which red, white, and blue indicate high, intermediate, and low intensities, respectively.

19. Heng TSP, Painter MW. Immunological Genome Project Consortium. The Immunological Genome Project: networks of gene expression in immune cells. Nat Immunol (2008) 9(10):1091-4. doi:10.1038/ni1008-1091

20. Stacey M, Chang GW, Sanos SL, Chittenden LR, Stubbs L, Gordon S, et al. EMR4, a novel epidermal growth factor (EGF)-TM7 molecule up-regulated in activated mouse macrophages, binds to a putative cellular ligand on $\mathrm{B}$ lymphoma cell line A20. J Biol Chem (2002) 277(32):29283-93. doi:10.1074/ jbc.M204306200

21. Jancso M. Histamine as a physiological activator of the reticulo-endothelial system. Nature (1947) 159(4059):227. doi:10.1038/160227a0

22. Panula $\mathrm{P}$, Yang $\mathrm{H}$, Costa E. Histamine-containing neurons in the rat hypothalamus. Proc Natl Acad Sci U S A (1984) 81(8):2572-6. doi:10.1073/ pnas.81.8.2572

23. Panula P, Airaksinen MS, Pirvola U, Kotilainen E. A histamine-containing neuronal system in human brain. Neuroscience (1990) 34(1):127-32. doi:10.1016/ 0306-4522(90)90307-P

24. Gözsy B, Kátó L. Studies on the effects of phagocytic stimulation on microbial disease. V. Stimulation of phagocytic activity of monocytes against tubercle bacilli, strain BCG. Can J Biochem Physiol (1956) 34(3):571-9. doi:10.1139/o56-062

25. Kátó L, Gözsy B. Action of histamine and antihistamine on the ingestion of murine leprosy bacilli by macrophages of the rat and the guinea-pig. Int J Lepr (1956) 24(4, Pt 1):447-56.

26. Northover BJ. The effect of histamine and 5-hydroxytryptamine on phagocytosis of staphylococci in vitro by polymorphs and macrophages. J Pathol Bacteriol (1961) 82:355-61. doi:10.1002/path.1700820213

27. Hench PS, Kendall EC, Slocumb CH, Polley HF. The effect of a hormone of the adrenal cortex (17-hydroxy-11-dehydrocorticosterone; compound E) and of pituitary adrenocorticotropic hormone on rheumatoid arthritis. Proc Staff Meet Mayo Clin (1949) 24(8):181-97.

28. Hench PS, Kendall EC, Slocumb CH, Polley HF. Effects of cortisone acetate and pituitary ACTH on rheumatoid arthritis, rheumatic fever and certain other conditions. Arch Intern Med (Chic) (1950) 85(4):545-666. doi:10.1001/ archinte.1950.00230100002001

29. Ragan C, Howes EL, Plotz CM, Meyer K, Blunt JW. Effect of cortisone on production of granulation tissue in the rabbit. Proc Soc Exp Biol Med (1949) 72(3):718-21. doi:10.3181/00379727-72-17555

30. Ragan C, Howes EL, Plotz CM, Meyer K, Blunt JW, Lattes R. The effect of ACTH and cortisone on connective tissue. Bull N Y Acad Med (1950) 26(4):251-4

31. Antopol W. Anatomic changes produced in mice treated with excessive doses of cortisone. Exp Biol Med (1950) 73(2):262-5. doi:10.3181/00379727-73-17648

32. Creditor MC, Bevans M, Mundy WL, Ragan C. Effect of ACTH on wound healing in humans. Proc Soc Exp Biol Med (1950) 74(1):245-7. doi:10.3181/ 00379727-74-17867

33. Heilman DH. The effect of 11-dehydro-17 hydroxycorticosterone and 11-dehydrocorticosterone on the migration of macrophages in tissue culture. Mayo Clin Proc (1945) 20:318.

34. Leahy RH, Morgan HR. The inhibition by cortisone of the cytotoxic activity of PPD on tuberculin-hypersensitive cells in tissue culture. J Exp Med (1952) 96(6):549-54. doi:10.1084/jem.96.6.549

35. Nauck M, Karakiulakis G, Roth M. Corticosteroids inhibit the expression of the vascular endothelial growth factor gene in human vascular smooth 
muscle cells. Eur J Pharmacol (1998) 341(2-3):309-15. doi:10.1016/S00142999(97)01464-7

36. Steinman L. Elaborate interactions between the immune and nervous systems. Nat Immunol (2004) 5(6):575-81. doi:10.1038/ni1078

37. Savino W, Mendes-da-Cruz DA, Lepletier A, Dardenne M. Hormonal control of T-cell development in health and disease. Nat Rev Endocrinol (2016) 12(2):77-89. doi:10.1038/nrendo.2015.168

38. Ginhoux F, Greter M, Leboeuf M, Nandi S, See P, Gokhan S, et al. Fate mapping analysis reveals that adult microglia derive from primitive macrophages. Science (2010) 330(6005):841-5. doi:10.1126/science.1194637

39. Schulz C, Gomez Perdiguero E, Chorro L, Szabo-Rogers H, Cagnard N, Kierdorf $\mathrm{K}$, et al. A lineage of myeloid cells independent of Myb and hematopoietic stem cells. Science (2012) 336(6077):86-90. doi:10.1126/science. 1219179

40. Gomez Perdiguero E, Klapproth K, Schulz C, Busch K, Azzoni E, Crozet L, et al. Tissue-resident macrophages originate from yolk-sac-derived erythromyeloid progenitors. Nature (2015) 518(7540):547-51. doi:10.1038/nature13989

41. Hoeffel G, Chen J, Lavin Y, Low D, Almeida FF, See P, et al. C-Myb(+) erythro-myeloid progenitor-derived fetal monocytes give rise to adult tissue-resident macrophages. Immunity (2015) 42(4):665-78. doi:10.1016/j. immuni.2015.03.011

42. McGrath KE, Frame JM, Fegan KH, Bowen JR, Conway SJ, Catherman SC, et al. Distinct sources of hematopoietic progenitors emerge before HSCs and provide functional blood cells in the mammalian embryo. Cell Rep (2015) 11(12):1892-904. doi:10.1016/j.celrep.2015.05.036

43. Sheng J, Ruedl C, Karjalainen K. Most tissue-resident macrophages except microglia are derived from fetal hematopoietic stem cells. Immunity (2015) 43(2):382-93. doi:10.1016/j.immuni.2015.07.016

44. Davies LC, Rosas M, Smith PJ, Fraser DJ, Jones SA, Taylor PR. A quantifiable proliferative burst of tissue macrophages restores homeostatic macrophage populations after acute inflammation. Eur J Immunol (2011) 41(8):2155-64. doi:10.1002/eji.201141817

45. Hashimoto D, Chow A, Noizat C, Teo P, Beasley MB, Leboeuf M, et al. Tissue-resident macrophages self-maintain locally throughout adult life with minimal contribution from circulating monocytes. Immunity (2013) 38(4):792-804. doi:10.1016/j.immuni.2013.04.004

46. Epelman S, Lavine KJ, Beaudin AE, Sojka DK, Carrero JA, Calderon B, et al. Embryonic and adult-derived resident cardiac macrophages are maintained through distinct mechanisms at steady state and during inflammation. Immunity (2014) 40(1):91-104. doi:10.1016/j.immuni.2013.11.019

47. Murray PJ, Allen JE, Biswas SK, Fisher EA, Gilroy DW, Goerdt S, et al. Macrophage activation and polarization: nomenclature and experimental guidelines. Immunity (2014) 41(1):14-20. doi:10.1016/j.immuni.2014.06.008

48. Martinez FO, Gordon $\mathrm{S}$. The M1 and M2 paradigm of macrophage activation: time for reassessment. F1000Prime Rep (2014) 6:13. doi:10.12703/P6-13

49. Mia S, Warnecke A, Zhang X-M, Malmström V, Harris RA. An optimized protocol for human M2 macrophages using M-CSF and IL-4/IL-10/TGF- $\beta$ yields a dominant immunosuppressive phenotype. Scand J Immunol (2014) 79(5):305-14. doi:10.1111/sji.12162

50. Mukhopadhyay D, Mukherjee S, Roy S, Dalton JE, Kundu S, Sarkar A, et al. M2 polarization of monocytes-macrophages is a hallmark of Indian post kala-azar dermal leishmaniasis. PLoS Negl Trop Dis (2015) 9(10):e0004145. doi:10.1371/journal.pntd.0004145

51. Rath M, Müller I, Kropf P, Closs EI, Munder M. Metabolism via arginase or nitric oxide synthase: two competing arginine pathways in macrophages. Front Immunol (2014) 5:532. doi:10.3389/fimmu.2014.00532

52. Bhatta A, Yao L, Toque HA, Shatanawi A, Xu Z, Caldwell RB, et al. Angiotensin II-induced arterial thickening, fibrosis and stiffening involves elevated arginase function. PLoS One (2015) 10(3):e0121727. doi:10.1371/ journal.pone. 0127110

53. Mills CD. Macrophage arginine metabolism to ornithine/urea or nitric oxide/citrulline: a life or death issue. Crit Rev Immunol (2001) 21(5):399-425. doi:10.1615/CritRevImmunol.v21.i5.10

54. Martinez FO, Sica A, Mantovani A, Locati M. Macrophage activation and polarization. Front Biosci (2008) 13(4):453-61. doi:10.2741/2692

55. Zizzo G, Hilliard BA, Monestier M, Cohen PL. Efficient clearance of early apoptotic cells by human macrophages requires M2c polarization and MerTK induction. J Immunol (2012) 189(7):3508-20. doi:10.4049/jimmunol. 1200662
56. Guiducci C, Vicari AP, Sangaletti S, Trinchieri G, Colombo MP. Redirecting in vivo elicited tumor infiltrating macrophages and dendritic cells towards tumor rejection. Cancer Res (2005) 65(8):3437-46. doi:10.1158/0008-5472. CAN-04-4262

57. Bystrom J, Evans I, Newson J, Stables M, Toor I, van Rooijen N, et al. Resolution-phase macrophages possess a unique inflammatory phenotype that is controlled by cAMP. Blood (2008) 112(10):4117-27. doi:10.1182/blood2007-12-129767

58. Varga T, Mounier R, Patsalos A, Gogolák P, Peloquin M, Horvath A, et al. Macrophage PPAR $\gamma$, a lipid activated transcription factor controls the growth factor GDF3 and skeletal muscle regeneration. Immunity (2016) 45(5):1038-51. doi:10.1016/j.immuni.2016.10.016

59. Gratchev A, Kzhyshkowska J, Utikal J, Goerdt S. Interleukin-4 and dexamethasone counterregulate extracellular matrix remodelling and phagocytosis in type-2 macrophages. Scand J Immunol (2005) 61(1):10-7. doi:10.1111/j.0300-9475.2005.01524.x

60. Gratchev A, Kzhyshkowska J, Kannookadan S, Ochsenreiter M, Popova A, Yu X, et al. Activation of a TGF-beta-specific multistep gene expression program in mature macrophages requires glucocorticoid-mediated surface expression of TGF-beta receptor II. J Immunol (2008) 180(10):6553-65. doi:10.4049/jimmunol.180.10.6553

61. Berrebi D, Bruscoli S, Cohen N, Foussat A, Migliorati G, Bouchet-Delbos L, et al. Synthesis of glucocorticoid-induced leucine zipper (GILZ) by macrophages: an anti-inflammatory and immunosuppressive mechanism shared by glucocorticoids and IL-10. Blood (2003) 101(2):729-38. doi:10.1182/ blood-2002-02-0538

62. Hoppstädter J, Kessler SM, Bruscoli S, Huwer H, Riccardi C, Kiemer AK. Glucocorticoid-induced leucine zipper: a critical factor in macrophage endotoxin tolerance. J Immunol (2015) 194(12):6057-67. doi:10.4049/jimmunol. 1403207

63. Ronchetti S, Migliorati G, Riccardi C. GILZ as a mediator of the antiinflammatory effects of glucocorticoids. Front Endocrinol (2015) 6:170. doi:10.3389/fendo.2015.00170

64. Kim BY, Son Y, Lee J, Choi J, Kim CD, Bae SS, et al. Dexamethasone inhibits activation of monocytes/macrophages in a milieu rich in 27 oxygenated cholesterol. PLoS One (2017) 12(12):e0189643. doi:10.1371/ journal.pone. 0189643

65. Grailer JJ, Haggadone MD, Sarma JV, Zetoune FS, Ward PA. Induction of M2 regulatory macrophages through the $\beta 2$-adrenergic receptor with protection during endotoxemia and acute lung injury. J Innate Immun (2014) 6(5):607-18. doi:10.1159/000358524

66. Barouch R, Kazimirsky G, Appel E, Brodie C. Nerve growth factor regulates TNF-alpha production in mouse macrophages via MAP kinase activation. J Leukoc Biol (2001) 69(6):1019-26. doi:10.1189/jlb.69.6.1019

67. Caroleo MC, Costa N, Bracci-Laudiero L, Aloe L. Human monocyte/ macrophages activate by exposure to LPS overexpress NGF and NGF receptors. J Neuroimmunol (2001) 113(2):193-201. doi:10.1016/S0165-5728(00) 00441-0

68. Garaci E, Caroleo MC, Aloe L, Aquaro S, Piacentini M, Costa N, et al. Nerve growth factor is an autocrine factor essential for the survival of macrophages infected with HIV. Proc Natl Acad Sci U S A (1999) 96(24):14013-8. doi:10.1073/ pnas.96.24.14013

69. Souza TML, Rodrigues DQ, Passaes CPB, Barreto-de-Souza V, Aguiar RS, Temerozo JR, et al. The nerve growth factor reduces APOBEC3G synthesis and enhances HIV-1 transcription and replication in human primary macrophages. Blood (2011) 117(10):2944-52. doi:10.1182/blood-2010-05-287193

70. Chiba R, Amagai Y, Tanaka A, Katakura K, Matsuda H. Nerve growth factor promotes killing of Leishmania donovani by macrophages through the induction of hydrogen peroxide. Microbes Infect (2014) 16(8):702-6. doi:10.1016/j. micinf.2014.06.001

71. Gonzalez-Rey E, Delgado M. Vasoactive intestinal peptide inhibits cycloxygenase-2 expression in activated macrophages, microglia, and dendritic cells. Brain Behav Immun (2008) 22(1):35-41. doi:10.1016/j.bbi.2007.07.004

72. Chen L, Yuan W, Chen Z, Wu S, Ge J, Chen J, et al. Vasoactive intestinal peptide represses activation of tumor-associated macrophages in gastric cancer via regulation of TNF $\alpha$, IL-6, IL-12 and iNOS. Int J Oncol (2015) 47: 1361-70. doi:10.3892/ijo.2015.3126

73. Carrion M, Perez-Garcia S, Martinez C, Juarranz Y, Estrada-Capetillo L, Puig-Kroger A, et al. VIP impairs acquisition of the macrophage proinflam- 
matory polarization profile.J Leukoc Biol (2016) 100(6):1385-93. doi:10.1189/ jlb.3A0116-032RR

74. Temerozo JR, Joaquim R, Regis EG, Savino W, Bou-Habib DC. Macrophage resistance to HIV-1 infection is enhanced by the neuropeptides VIP and PACAP. PLoS One (2013) 8(6):e67701. doi:10.1371/journal.pone.0067701

75. Brifault C, Gras M, Liot D, May V, Vaudry D, Wurtz O. Delayed pituitary adenylate cyclase-activating polypeptide delivery after brain stroke improves functional recovery by inducing M2 microglia/macrophage polarization. Stroke (2015) 46(2):520-8. doi:10.1161/STROKEAHA.114.006864

76. Shi C, Pamer EG. Monocyte recruitment during infection and inflammation. Nat Rev Immunol (2011) 11(11):762-74. doi:10.1038/nri3070

77. De la Fuente M, Bernaez I, Del Rio M, Hernanz A. Stimulation of murine peritoneal macrophage functions by neuropeptide Y and peptide YY. Involvement of protein kinase C. Immunology (1993) 80(2):259-65.

78. Ahmed AA, Wahbi A, Nordlind K, Kharazmi A, Sundqvist KG, Mutt V, et al. In vitro Leishmania major promastigote-induced macrophage migration is modulated by sensory and autonomic neuropeptides. Scand J Immunol (1998) 48(1):79-85. doi:10.1046/j.1365-3083.1998.00380.x

79. Spitsin S, Meshki J, Winters A, Tuluc F, Benton TD, Douglas SD. Substance $\mathrm{P}-$ mediated chemokine production promotes monocyte migration. J Leukoc Biol (2017) 101(4):967-73. doi:10.1189/jlb.1AB0416-188RR

80. Jiang W, St-Pierre S, Roy P, Morley BJ, Hao J, Simard AR. Infiltration of CCR2+Ly6Chigh proinflammatory monocytes and neutrophils into the central nervous system is modulated by nicotinic acetylcholine receptors in a model of multiple sclerosis. J Immunol (2016) 196(5):2095-108. doi:10.4049/ jimmunol.1501613

81. Mojumdar K, Liang F, Giordano C, Lemaire C, Danialou G, Okazaki T, et al. Inflammatory monocytes promote progression of Duchenne muscular dystrophy and can be therapeutically targeted via CCR2. EMBO Mol Med (2014) 6(11):1476-92. doi:10.15252/emmm.201403967

82. Fink G. Stress, definitions, mechanisms, and effects outlined: lessons from anxiety. In: Fink G, editor. Stress Concepts, Cogn Emot Behav - Handb Stress. (Vol. 1), London: Academic Press \& Elsevier (2016). p. 3-11.

83. Rollins DA, Kharlyngdoh JB, Coppo M, Tharmalingam B, Mimouna S, Guo Z, et al. Glucocorticoid-induced phosphorylation by CDK9 modulates the coactivator functions of transcriptional cofactor GRIP1 in macrophages. Nat Commun (2017) 8(1):1739. doi:10.1038/s41467-017-01569-2

84. Chinenov Y, Coppo M, Gupte R, Sacta MA, Rogatsky I. Glucocorticoid receptor coordinates transcription factor-dominated regulatory network in macrophages. BMC Genomics (2014) 15(1):656. doi:10.1186/14712164-15-656

85. Viguerie N, Clement K, Barbe P, Courtine M, Benis A, Larrouy D, et al. In vivo epinephrine-mediated regulation of gene expression in human skeletal muscle. J Clin Endocrinol Metab (2004) 89(5):2000-14. doi:10.1210/jc. 2003-031733

86. Kolmus K, Tavernier J, Gerlo S. $\beta 2$-Adrenergic receptors in immunity and inflammation: stressing NF-KB. Brain Behav Immun (2015) 45:297-310. doi:10.1016/j.bbi.2014.10.007

87. American Psychological Association. Stress in America: Coping with Change. Stress in America ${ }^{T M}$ Survey. Washington, DC: American Psychological Association (2017).

88. Engler H, Bailey MT, Engler A, Sheridan JF. Effects of repeated social stress on leukocyte distribution in bone marrow, peripheral blood and spleen. J Neuroimmunol (2004) 148(1-2):106-15. doi:10.1016/j.jneuroim.2003. 11.011

89. Trottier MD, Newsted MM, King LE, Fraker PJ. Natural glucocorticoids induce expansion of all developmental stages of murine bone marrow granulocytes without inhibiting function. Proc Natl Acad Sci U S A (2008) 105(6):2028-33. doi:10.1073/pnas.0712003105

90. Wang X, Li Y, Zhu X, Wang Y, Diao F, Lu J. Signal regulatory protein alpha1 is involved in the inhibitory effect of glucocorticoid receptor on the proliferation of murine macrophage RAW264.7 cell and mouse peritoneal macrophage. J Mol Endocrinol (2008) 41(5):393-403. doi:10.1677/JME-08-0021

91. Rinehart JJ, Balcerzak SP, Sagone AL, LoBuglio AF. Effects of corticosteroids on human monocyte function. JClin Invest (1974) 54(6):1337-43. doi:10.1172/JCI107880

92. Okutsu M, Suzuki K, Ishijima T, Peake J, Higuchi M. The effects of acute exercise-induced cortisol on CCR2 expression on human monocytes. Brain Behav Immun (2008) 22(7):1066-71. doi:10.1016/j.bbi.2008.03.006
93. Yeager MP, Pioli PA, Collins J, Barr F, Metzler S, Sites BD, et al. Glucocorticoids enhance the in vivo migratory response of human monocytes. Brain Behav Immun (2016) 54:86-94. doi:10.1016/j.bbi.2016.01.004

94. Teshima H, Sogawa H, Kihara H, Kubo C, Mori K, Nakagawa T. Prevention of immunosuppression in stressed mice by neurotropin(NSP). Life Sci (1990) 47(10):869-76. doi:10.1016/0024-3205(90)90600-V

95. Palermo-Neto J, de Oliveira Massoco C, Robespierre de Souza W. Effects of physical and psychological stressors on behavior, macrophage activity, and Ehrlich tumor growth. Brain Behav Immun (2003) 17(1):43-54. doi:10.1016/ S0889-1591(02)00057-0

96. Sesti-Costa R, Baccan GC, Chedraoui-Silva S, Mantovani B. Effects of acute cold stress on phagocytosis of apoptotic cells: the role of corticosterone. Neuroimmunomodulation (2010) 17(2):79-87. doi:10.1159/000258690

97. Quinteiro-Filho WM, Rodrigues MV, Ribeiro A, Ferraz-de-Paula V, Pinheiro ML, Sá LRM, et al. Acute heat stress impairs performance parameters and induces mild intestinal enteritis in broiler chickens: role of acute hypothalamicpituitary-adrenal axis activation. J Anim Sci (2012) 90(6):1986-94. doi:10.2527/ jas.2011-3949

98. Elenkov IJ, Chrousos GP. Stress hormones, proinflammatory and antiinflammatory cytokines, and autoimmunity. Ann N Y Acad Sci (2002) 966(1): 290-303. doi:10.1111/j.1749-6632.2002.tb04229.x

99. Cohen S, Janicki-Deverts D, Doyle WJ, Miller GE, Frank E, Rabin BS, et al. Chronic stress, glucocorticoid receptor resistance, inflammation, and disease risk. Proc Natl Acad Sci U S A (2012) 109(16):5995-9. doi:10.1073/ pnas. 1118355109

100. Warren MK, Vogel SN. Opposing effects of glucocorticoids on interferongamma-induced murine macrophage $\mathrm{Fc}$ receptor and Ia antigen expression. J Immunol (1985) 134(4):2462-9.

101. Chapman KE, Coutinho A, Gray M, Gilmour JS, Savill JS, Seckl JR. Local amplification of glucocorticoids by 11 beta-hydroxysteroid dehydrogenase type 1 and its role in the inflammatory response. Ann N Y Acad Sci (2006) 1088(1):265-73. doi:10.1196/annals.1366.030

102. Liu Y, Cousin JM, Hughes J, Van Damme J, Seckl JR, Haslett C, et al. Glucocorticoids promote nonphlogistic phagocytosis of apoptotic leukocytes. J Immunol (1999) 162(6):3639-46.

103. Voll RE, Herrmann M, Roth EA, Stach C, Kalden JR, Girkontaite I. Immunosuppressive effects of apoptotic cells. Nature (1997) 390(6658):350-1. doi: $10.1038 / 37022$

104. Lucas M, Stuart LM, Zhang A, Hodivala-Dilke K, Febbraio M, Silverstein R, et al. Requirements for apoptotic cell contact in regulation of macrophage responses. J Immunol (2006) 177(6):4047-54. doi:10.4049/jimmunol.177. 6.4047

105. Yamaguchi H, Maruyama T, Urade Y, Nagata S. Immunosuppression via adenosine receptor activation by adenosine monophosphate released from apoptotic cells. Elife (2014) 2014(3):1-15. doi:10.7554/eLife.02172

106. Cheng GJ, Morrow-Tesch JL, Beller DI, Levy EM, Black PH. Immunosuppression in mice induced by cold water stress. Brain Behav Immun (1990) 4(4):278-91. doi:10.1016/0889-1591(90)90032-L

107. Zwilling BS, Dinkins M, Christner R, Faris M, Griffin A, Hilburger M, et al. Restraint stress-induced suppression of major histocompatibility complex class II expression by murine peritoneal macrophages. J Neuroimmunol (1990) 29(1-3):125-30. doi:10.1016/0165-5728(90)90154-F

108. Zwilling BS, Brown D, Christner R, Faris M, Hilburger M, McPeek M, et al. Differential effect of restraint stress on MHC class II expression by murine peritoneal macrophages. Brain Behav Immun (1990) 4(4):330-8. doi:10.1016/0889-1591(90)90036-P

109. Kizaki T, Oh-ishi S, Ookawara T, Yamamoto M, Izawa $\mathrm{T}$, Ohno $\mathrm{H}$. Glucocorticoid-mediated generation of suppressor macrophages with high density Fc gamma RII during acute cold stress. Endocrinology (1996) 137(10):4260-7. doi:10.1210/endo.137.10.8828485

110. Kizaki T, Oh-ishi S, Ohno H. Acute cold stress induces suppressor macrophages in mice. J Appl Physiol (1996) 81(1):393-9. doi:10.1152/jappl.1996.81.1.393

111. Nguyen KD, Qiu Y, Cui X, Goh YPS, Mwangi J, David T, et al. Alternatively activated macrophages produce catecholamines to sustain adaptive thermogenesis. Nature (2011) 480(7375):104-8. doi:10.1038/nature10653

112. Takahashi H, Tsuda Y, Kobayashi M, Herndon DN, Suzuki F. Increased norepinephrine production associated with burn injuries results in CCL2 production and type $2 \mathrm{~T}$ cell generation. Burns (2004) 30(4):317-21. doi:10.1016/j.burns.2003.12.005 
113. Visser J, van Boxel-Dezaire A, Methorst D, Brunt T, de Kloet ER, Nagelkerken L. Differential regulation of interleukin-10 (IL-10) and IL-12 by glucocorticoids in vitro. Blood (1998) 91(11):4255-64.

114. Blotta MH, DeKruyff RH, Umetsu DT. Corticosteroids inhibit IL-12 production in human monocytes and enhance their capacity to induce IL-4 synthesis in CD4+ lymphocytes. J Immunol (1997) 158(12):5589-95.

115. Brown DH, Zwilling BS. Activation of the hypothalamic-pituitary-adrenal axis differentially affects the anti-mycobacterial activity of macrophages from BCG-resistant and susceptible mice. J Neuroimmunol (1994) 53(2):181-7. doi:10.1016/0165-5728(94)90028-0

116. Pavlov VA, Tracey KJ. The vagus nerve and the inflammatory reflex - linking immunity and metabolism. Nat Rev Endocrinol (2012) 8(12):743-54. doi:10.1038/nrendo.2012.189

117. Henry TR. Therapeutic mechanisms of vagus nerve stimulation. Neurology (2002) 59(6 Suppl 4):S3-14. doi:10.1212/wnl.59.6_suppl_4.s3

118. Bonaz B, Sinniger V, Pellissier S. The vagus nerve in the neuro-immune axis: implications in the pathology of the gastrointestinal tract. Front Immunol (2017) 8:1452. doi:10.3389/fimmu.2017.01452

119. Sato E, Koyama S, Okubo Y, Kubo K, Sekiguchi M. Acetylcholine stimulates alveolar macrophages to release inflammatory cell chemotactic activity. Am J Physiol (1998) 274(6 Pt 1):L970-9. doi:10.1152/ajplung.1998.274.6.L970

120. Sato KZ, Fujii T, Watanabe Y, Yamada S, Ando T, Kazuko F, et al. Diversity of mRNA expression for muscarinic acetylcholine receptor subtypes and neuronal nicotinic acetylcholine receptor subunits in human mononuclear leukocytes and leukemic cell lines. Neurosci Lett (1999) 266(1):17-20. doi:10.1016/S0304-3940(99)00259-1

121. Wang H, Yu M, Ochani M, Amella CA, Tanovic M, Susarla S, et al. Nicotinic acetylcholine receptor $\alpha 7$ subunit is an essential regulator of inflammation. Nature (2003) 421(6921):384-8. doi:10.1038/nature01339

122. Kawashima K, Yoshikawa K, Fujii YX, Moriwaki Y, Misawa H. Expression and function of genes encoding cholinergic components in murine immune cells. Life Sci (2007) 80(24-25):2314-9. doi:10.1016/j.lfs.2007.02.036

123. Koarai A, Traves SL, Fenwick PS, Brown SM, Chana KK, Russell REK, et al. Expression of muscarinic receptors by human macrophages. Eur Respir J (2012) 39(3):698-704. doi:10.1183/09031936.00136710

124. Fujii T, Mashimo M, Moriwaki Y, Misawa H, Ono S, Horiguchi K, et al. Physiological functions of the cholinergic system in immune cells. $J$ Pharmacol Sci (2017) 134(1):1-21. doi:10.1016/j.jphs.2017.05.002

125. Cailotto C, Gomez-Pinilla PJ, Costes LM, Van Der Vliet J, Di Giovangiulio M, Némethova A, et al. Neuro-anatomical evidence indicating indirect modulation of macrophages by vagal efferents in the intestine but not in the spleen. PLoS One (2014) 9(1). doi:10.1371/journal.pone.0087785

126. Borovikova LV, Ivanova S, Zhang M, Yang H, Botchkina GI, Watkins LR, et al. Vagus nerve stimulation attenuates the systemic inflammatory response to endotoxin. Nature (2000) 405(6785):458-62. doi:10.1038/35013070

127. Li Y, Xu Z, Yu Y, Yuan H, Xu H, Zhu Q, et al. The vagus nerve attenuates fulminant hepatitis by activating the src kinase in kuppfer cells. Scand $J$ Immunol (2014) 79(2):105-12. doi:10.1111/sji.12141

128. de Jonge WJ, van der Zanden EP, The FO, Bijlsma MF, van Westerloo DJ, Bennink RJ, et al. Stimulation of the vagus nerve attenuates macrophage activation by activating the Jak2-STAT3 signaling pathway. Nat Immunol (2005) 6(8):844-51. doi:10.1038/ni1229

129. Ghia JE, Blennerhassett P, Kumar-Ondiveeran H, Verdu EF, Collins SM. The vagus nerve: a tonic inhibitory influence associated with inflammatory bowel disease in a murine model. Gastroenterology (2006) 131(4):1122-30. doi:10.1053/j.gastro.2006.08.016

130. Inoue T, Abe C, Sung SSJ, Moscalu S, Jankowski J, Huang L, et al. Vagus nerve stimulation mediates protection from kidney ischemia-reperfusion injury through a7nAChR+splenocytes. J Clin Invest (2016) 126(5):1939-52. doi:10.1172/JCI83658

131. Bassi GS, Ulloa L, Santos VR, Del Vecchio F, Delfino-Pereira P, Rodrigues GJ, et al. Cortical stimulation in conscious rats controls joint inflammation. Prog Neuro-Psychopharmacology Biol Psychiatry (2018) 84:201-13. doi:10.1016/j.pnpbp.2018.02.013

132. Chapman K, Holmes M, Seckl J.11ß-hydroxysteroid dehydrogenases: intracellular gate-keepers of tissue glucocorticoid action. Physiol Rev (2013) 93(3):1139-206. doi:10.1152/physrev.00020.2012

133. Thieringer R, Le Grand CB, Carbin L, Cai TQ, Wong B, Wright SD, et al. $11 \beta$-hydroxysteroid dehydrogenase type 1 is induced in human monocytes upon differentiation to macrophages. J Immunol (2001) 167(1):30-5. doi:10.4049/jimmunol.167.1.30

134. Kunnathully V, Gomez-Lira M, Bassi G, Poli F, Zoratti E, La Verde V, et al. CD14++ CD16- monocytes are the main source of 11ß-HSD type 1 after IL-4 stimulation. Int Immunopharmacol (2017) 43:156-63. doi:10.1016/j. intimp.2016.12.015

135. Gottfried-Blackmore A, Sierra A, Mcewen BS, Ge R, Bulloch K. Microglia express functional 11ß-hydroxysteroid dehydrogenase type 1. Glia (2010) 58(10):1257-66. doi:10.1002/glia.21007

136. Baccan GC, Sesti-Costa R, Chedraoui-Silva S, Mantovani B. Effects of cold stress, corticosterone and catecholamines on phagocytosis in mice: differences between resting and activated macrophages. Neuroimmunomodulation (2010) 17(6):379-85. doi:10.1159/000292058

137. Sesti-Costa R, Ignacchiti MDC, Chedraoui-Silva S, Marchi LF, Mantovani B. Chronic cold stress in mice induces a regulatory phenotype in macrophages: correlation with increased 11 $\beta$-hydroxysteroid dehydrogenase expression. Brain Behav Immun (2012) 26(1):50-60. doi:10.1016/j.bbi.2011.07.234

138. Gabanyi I, Muller PA, Feighery L, Oliveira TY, Costa-Pinto FA, Mucida D. Neuro-immune interactions drive tissue programming in intestinal macrophages. Cell (2016) 164(3):378-91. doi:10.1016/j.cell.2015.12.023

139. Qian L, Wu H, Chen S-H, Zhang D, Ali SF, Peterson L, et al. $\beta 2$-adrenergic receptor activation prevents rodent dopaminergic neurotoxicity by inhibiting microglia via a novel signaling pathway. J Immunol (2011) 186(7):4443-54. doi:10.4049/jimmunol.1002449

140. Wang Y, Cella M, Mallinson K, Ulrich JD, Young KL, Robinette ML, et al. TREM2 lipid sensing sustains the microglial response in an Alzheimer's disease model. Cell (2015) 160(6):1061-71. doi:10.1016/j.cell.2015.01.049

141. Suzuki S, Tsubochi H, Ishibashi H, Suzuki T, Kondo T, Sasano H. Increased expression of 11 beta-hydroxysteroid dehydrogenase type 2 in the lungs of patients with acute respiratory distress syndrome. Pathol Int (2003) 53(11):751-6. doi:10.1046/j.1440-1827.2003.01561.x

142. Schmidt M, Weidler C, Naumann H, Anders S, Schölmerich J, Straub RH. Reduced capacity for the reactivation of glucocorticoids in rheumatoid arthritis synovial cells: possible role of the sympathetic nervous system? Arthritis Rheum (2005) 52(6):1711-20. doi:10.1002/art.21091

143. Haas CS, Creighton CJ, Pi X, Maine I, Koch AE, Haines GK, et al. Identification of genes modulated in rheumatoid arthritis using complementary DNA microarray analysis of lymphoblastoid B cell lines from disease-discordant monozygotic twins. Arthritis Rheum (2006) 54(7):2047-60. doi:10.1002/ art.21953

144. Woiciechowsky C, Schöning B, Lanksch WR, Volk H-D, Döcke W-D. Catecholamine-induced interleukin-10 release: a key mechanism in systemic immunodepression after brain injury. Crit Care (1999) 3(6):R107. doi:10.1186/ cc375

145. Gallowitsch-Puerta M, Pavlov VA. Neuro-immune interactions via the cholinergic anti-inflammatory pathway. Life Sci (2007) 80(24-25): 2325-9. doi:10.1016/j.lfs.2007.01.002

146. Bencze M, Negroni E, Vallese D, Yacoubyoussef H, Chaouch S, Wolff A, et al. Proinflammatory macrophages enhance the regenerative capacity of human myoblasts by modifying their kinetics of proliferation and differentiation. Mol Ther (2012) 20(11):2168-79. doi:10.1038/mt.2012.189

147. Lesault P-F, Theret M, Magnan M, Cuvellier S, Niu Y, Gherardi RK, et al. Macrophages improve survival, proliferation and migration of engrafted myogenic precursor cells into MDX skeletal muscle. PLoS One (2012) 7(10):e46698. doi:10.1371/journal.pone.0046698

148. Arnold L, Henry A, Poron F, Baba-Amer Y, van Rooijen N, Plonquet A, et al. Inflammatory monocytes recruited after skeletal muscle injury switch into antiinflammatory macrophages to support myogenesis. J Exp Med (2007) 204(5):1057-69. doi:10.1084/jem.20070075

149. Chazaud B, Brigitte M, Yacoub-Youssef H, Arnold L, Gherardi R, Sonnet C, et al. Dual and beneficial roles of macrophages during skeletal muscle regeneration. Exerc Sport Sci Rev (2009) 37(1):18-22. doi:10.1097/JES. 0b013e318190ebdb

150. Lin KT, Sun SP, Wu JI, Wang LH. Low-dose glucocorticoids suppresses ovarian tumor growth and metastasis in an immunocompetent syngeneic mouse model. PLoS One (2017) 12(6):e0178937. doi:10.1371/journal.pone.0178937

151. Tariq M, Zhang J, Liang G, Ding L, He Q, Yang B. Macrophage polarization: anti-cancer strategies to target tumor-associated macrophage in breast cancer. J Cell Biochem (2017) 118(9):2484-501. doi:10.1002/jcb.25895 
152. Relation T, Yi T, Guess AJ, La Perle K, Otsuru S, Hasgur S, et al. Intratumoral delivery of interferon $\gamma$-secreting MSCs repolarizes tumor-associated macrophages and suppresses neuroblastoma proliferation in vivo. Stem Cells (2018) 36(6):915-24. doi:10.1002/stem.2801

153. Ma P-F, Gao C-C, Yi J, Zhao J-L, Liang S-Q, Zhao Y, et al. Cytotherapy with M1-polarized macrophages ameliorates liver fibrosis by modulating immune microenvironment in mice. J Hepatol (2017) 67(4):770-9. doi:10.1016/j. jhep.2017.05.022

154. Song GJ, Suk K. Pharmacological modulation of functional phenotypes of microglia in neurodegenerative diseases. Front Aging Neurosci (2017) 9:139. doi:10.3389/fnagi.2017.00139

155. Cherry JD, Olschowka JA, O’Banion MK. Neuroinflammation and M2 microglia: the good, the bad, and the inflamed. J Neuroinflammation (2014) 11(1):98. doi:10.1186/1742-2094-11-98

156. Ziemssen T, Schrempf W. Glatiramer acetate: mechanisms of action in multiple sclerosis. Int Rev Neurobiol (2007) 79(07):537-70. doi:10.1016/ S0074-7742(07)79024-4

157. Batchelor PE, Liberatore GT, Wong JY, Porritt MJ, Frerichs F, Donnan GA, et al. Activated macrophages and microglia induce dopaminergic sprouting in the injured striatum and express brain-derived neurotrophic factor and glial cell line-derived neurotrophic factor. J Neurosci (1999) 19(5):1708-16. doi:10.1523/JNEUROSCI.19-05-01708.1999

158. Zhang XM, Lund H, Mia S, Parsa R, Harris RA. Adoptive transfer of cytokine-induced immunomodulatory adult microglia attenuates experimental autoimmune encephalomyelitis in DBA/1 mice. Glia (2014) 62(5):804-17. doi:10.1002/glia.22643
159. Miron VE, Boyd A, Zhao JW, Yuen TJ, Ruckh JM, Shadrach JL, et al. M2 microglia and macrophages drive oligodendrocyte differentiation during CNS remyelination. Nat Neurosci (2013) 16(9):1211-8. doi:10.1038/ nn.3469

160. Xu X, Gao W, Cheng S, Yin D, Li F, Wu Y, et al. Anti-inflammatory and immunomodulatory mechanisms of atorvastatin in a murine model of traumatic brain injury. J Neuroinflammation (2017) 14(1):1-15. doi:10.1186/ s12974-017-0934-2

161. Yadav A, Betts MR, Collman RG. Statin modulation of monocyte phenotype and function: implications for HIV-1-associated neurocognitive disorders. J Neurovirol (2016) 22(5):584-96. doi:10.1007/s13365-016-0433-8

162. Beyer M, Mallmann MR, Xue J, Staratschek-Jox A, Vorholt D, Krebs W, et al. High-resolution transcriptome of human macrophages. PLoS One (2012) 7(9):e45466. doi:10.1371/journal.pone.0045466

Conflict of Interest Statement: The authors declare that the research was conducted in the absence of any commercial or financial relationships that could be construed as a potential conflict of interest.

Copyright (c) 2018 Jurberg, Cotta-de-Almeida, Temerozo, Savino, Bou-Habib and Riederer. This is an open-access article distributed under the terms of the Creative Commons Attribution License (CC BY). The use, distribution or reproduction in other forums is permitted, provided the original author(s) and the copyright owner are credited and that the original publication in this journal is cited, in accordance with accepted academic practice. No use, distribution or reproduction is permitted which does not comply with these terms. 